\title{
REFLEXÃO HISTÓRICA SOBRE A IMPORTÂNCIA DA EDUCAÇÃO NO PENSAMENTO DE ARISTÓTELES
}

\section{HISTORICAL REFLECTION ON THE IMPORTANCE OF EDUCATION IN THE THOUGHT OF ARISTOTLE}

\author{
Mariclaudia Aparecida de Abreu ${ }^{1}$ \\ Carlos Herold Junior ${ }^{2}$
}

\section{RESUMO}

O objetivo deste trabalho é analisar como ocorre o processo de formação do homem livre e a relação estabelecida com as virtudes, a vida social e política no pensamento aristotélico. Para isso, dividimos o texto em duas partes. Na primeira parte, fazemos uma análise histórica da educação grega. Na segunda, mostramos a relação entre ética e educação e entre educação e política. Como conclusão, observamos que no pensamento aristotélico a questão educacional é entendida pelo viés da política, sendo um instrumento importante para o Estado garantir a formação dos novos dirigentes da polis.

Palavras-chave: Aristóteles. Ética. Política. Educação.

\begin{abstract}
The aim of this study is to analyze how the formation process of the free man takes place and its relationship with virtues, social and political life in the Aristotelian thought. The text is divided into two parts; in the first part, a historical analysis of the Greek education is presented. In the second part, the relationship between ethics and education and between education and politics is analyzed. It was observed that in Aristotelian thought education is seen from a political point of view being an important instrument for the State to guarantee the formation of the new leaders of the polis.
\end{abstract}

Keywords: Aristotle. Ethics. Politics. Education.

\footnotetext{
${ }^{1}$ Mariclaudia Aparecida de Abreu - Graduada em Pedagogia - UNICENTRO

${ }^{2}$ Prof. Dr. Carlos Herold Junior - Professor Adjunto do Departamento de Pedagogia da UNICENTRO - E-mail: carlosherold@bol.com.br
} 
A importância dos estudos históricos e filosóficos sobre a antiguidade não precisa de justificativas para ser endossada. $\mathrm{O}$ ocaso da pujança econômica, política e militar dos helenos não foi suficiente para impedir a divulgação de sua riqueza cultural. Esse valor, mediado por séculos de leituras, releituras, pesquisas e achados, culminou na tão conhecida assunção de que a Grécia antiga é "berço" da "civilização ocidental".

Dentro da gigantesca gama de autores e assuntos que compõem esse "berço", a amplitude da obra de Aristóteles também é um fato que dispensa maiores discussões. Entretanto, em que pese sua importância nos mais variados campos do conhecimento, as consequências educacionais de sua filosofia têm merecido uma atenção bem menor, se comparada à quantidade de inquietação que o filósofo causou, praticamente, em todos os campos do saber.

Apesar de algumas menções às suas ideias educacionais, ele não é estudado de maneira mais detalhada por aqueles que se interessam pela problemática educacional. Hourdakis (2001) explica que o desinteresse dos estudiosos pela questão educacional na obra de Aristóteles pode estar vinculado ao ponto de vista de alguns pesquisadores que não veem nele a originalidade criativa de Platão e de Isócrates. Esse é um fato que, no entendimento de Hourdakis, deve ser revisto. Afinal:

Aristóteles poderia ser caracterizado como politólogo e o médico da educação, que sente a necessidade de formular uma teoria de caráter reformador e fisiopedagógico, de maneira metódica e em profundidade, permanecendo mais realista do que seu mestre Platão (HOURDAKIS, 2001, p. 10).

Outro ponto importante apontado por Hourdakis e que merece destaque é a maneira com que Aristóteles pontuou problemáticas educacionais que ainda intrigam especialistas. Podemos encontrar em seu pensamento questões que nos preocupam ainda hoje, como, por exemplo, a relação teoria/prática, a questão da felicidade e, até mesmo, o problema do que ensinar e com que prioridade.

No presente estudo, temos a intenção de analisar a questão da concepção aristotélica sobre a educação, com base em duas de suas obras, A Política e Ética a Nicômaco, assumindo-as como componentes do contexto histórico-social da Grécia. Para isso, iniciamos nosso estudo sinalizando para o fato de que o que foi pensado por Aristóteles relacionava-se com questões culturais e sociais do mundo grego. Tomamos, então, o cuidado de apresentar as ideias de Aristóteles como não desvinculadas de um contexto e, em certa medida, como possibilitadas e/ou estimuladas pelo conjunto de transformações histórico-sociais que levaram à Grécia Clássica e a sustentaram.

No segundo momento da análise, tendo por base as lutas históricas que culminaram no surgimento da polis e de seus debates, adentramos, especificamente, nas concepções aristotélicas e procuramos mostrar a relação entre ética e educação, em que o problema central é a questão da felicidade e dos meios para atingi-la em consonância com a razão, considerando as necessidades colocadas pela perpetuação da vida política.

\section{A educação grega como objeto da história}

Muitos historiadores, segundo Cambi (1999), falam dos desenvolvimentos culturais da Grécia como "o milagre grego", devido à sua originalidade cultural, política e social, a qual era vista como rumando, inexoravelmente, em direção à racionalização, à laicização e à desvinculação do mito. Essa "originalidade", pondera Cambi (1999), deve ser vista, por outro lado, como um complexo jogo relacional entre diferentes culturas, histórias e geografias.

No que tange à educação, Marrou (1975) defende que a nossa tradição pedagógica tem sua origem na Grécia Antiga e, por isso, para melhor entendermos do que somos herdeiros, o olhar voltado aos helenos seria fundamental para a reflexão sobre os dilemas educacionais da atualidade. Em sua obra, Marrou (1975) faz isso, refazendo o caminho a partir de Homero, passando pela Grécia helenística, Roma e sua decadência.

Manacorda (1992, p.41) escreve que: "Ao se falar da Grécia só se pode começar com Homero, 'o educador de toda Grécia', como dizia Platão”. Giles $(1987$, p.12) também ressalta a importância dos poemas homéricos, afirmando que: "Os seus heróis servem de modelo permanente para toda a juventude". Ou seja, a virtude desses heróis foi o que inspirou todo o processo educativo na Grécia. A "pedagogia homérica" tinha como base o exemplo, cujo modelo ideal é representado por Aquiles. Segundo Jaeger (2003), 
a importância das narrativas sobre as características de Aquiles teve grande peso na formação de muitas gerações subsequentes:

$\mathrm{O}$ seu heroísmo não pertence ao tipo ingênuo e elementar daquele dos antigos heróis. Eleva-se até a escolha deliberada de uma grande façanha, ao preço antecipadamente conhecido, da própria vida. Todos os gregos posteriores concordam com essa interpretação e vêem nisto a grandeza moral e eficácia educadora do poema (...) Deve-se concluir que a Ilíada tem uma intenção ética. (JAEGER, 2003, p.75).

A morte de Aquiles representa o destino do qual ninguém poderia fugir, mas também a honra e a glória de enfrentá-lo a qualquer custo: "Aquiles e Ulisses serão também modelo da verdadeira virtude, da honra e da superioridade no cumprimento do dever" (GILES, 1987, p.12).

Notamos que em Homero o homem não pode negar o destino, mas posiciona-se frente a ele com coragem e bravura. Conforme afirma Giles (1987), o ideal educativo a ser alcançado é o herói, o melhor, o superior aos demais. Para isso, a forma de educação deveria ser condizente com a organização social daquele período, que era "dividida em reinos governados por reis-guerreiros, expressão de uma casta de dominadores militares, onde se vive de agricultura e pastoreio, mas também de comércio, e onde se organiza uma sociedade hierárquica, na qual o poder está nas mãos da aristocracia" (CAMBI, 1999, p.76).

Segundo nos relata Marrou (1975), o fato fundamental da cultura desse período é o privilégio de uma aristocracia de guerreiros, cuja ética se fundamenta no "amor da glória" (MARROU, 1975. p. 28). A educação heróica que é representada na Ilíada, segundo nos relata Cambi (1999), une língua, mão e cuidados com o corpo. Essa educação não se destinava a qualquer pessoa, mas aos aristocratas. Os jovens da aristocracia eram reunidos no palácio do rei, onde treinavam para a arte da guerra por meio de jogos e competições. A meta não era, simplesmente, a força física, mas também a astúcia e a inteligência:

O espírito de luta é aqui o critério educativo fundamental, que abrange tanto o aspecto físico-esportivo quanto o cortês-oratório-musical, solicitando exercícios com lira, dança e canto e remetendo o jovem também a práticas religiosas como a 'leitura dos signos, os ritos do sacrifício, o culto dos deuses e dos heróis' (CAMBI, 1999, p.77).
No entanto, por volta de 800 a.C., segundo Giles (1987), a antiga estrutura social dos tempos homéricos cede lugar a uma nova ordem: as cidades-estados, que trouxeram consigo a exigência da participação da vida pública e a demarcação do que seria o cidadão, têm no seu bojo aquilo que Jaeger chama de "Arete política". Conforme Jaeger (2003, p.145), diferentemente de um poder político que pertencia somente aos aristocratas, a situação que vai se formando, mesmo mantendo a sustentação no "Proferir belas palavras e realizar ações", organizou-se, depois de muitas crises e lutas, de forma democrática. Representativa dessas lutas e transformações é a importância que passaram a ter Esparta e Atenas. Cambi sintetiza a maneira como as diferenças entre essas duas cidades marcaram a história da Grécia, como um todo, bem como sua educação:

Esparta foi o modelo de Estado totalitário; Atenas, de democrático, e de uma democracia muito avançada. Até seus ideais e modelos educativos se caracterizam de maneira oposta pela perspectiva militar de formação de cidadãos-guerreiros, homogêneos à ideologia de uma sociedade fechada e compacta, ou por um tipo de formação cultural e aberta, que valoriza o indivíduo e suas capacidades de construção do próprio mundo interior e social. Esparta e Atenas deram vida a dois ideais de educação: um baseado no conformismo e no estatismo, outro na concepção de Paidéia, de formação humana livre e nutrida de experiências diversas, sociais, mas também culturais e antropológicas (CAMBI, 1999, p.82).

Marrou (1975), no entanto, apresenta-nos uma Esparta diferente daquela costumeiramente concebida. Embora não aprofunde a questão, mostra que, por volta do século VIII a.C., Esparta tem um lugar de destaque na educação e na cultura helênicas. Duas fontes lhe fornecem material para essa diferenciada concepção de Esparta:

(...) os fragmentos dos grandes líricos: Tirteu, Àlcman, e os resultados surpreendentes, das escavações feitas pela Escola Inglesa de Atenas, notadamente as do santuário de Ârtemis Ortia (1906-1910). A aproximação destas duas séries de fontes, que se esclarecem mutuamente, revela uma Esparta bem destoante daquela imagem tradicional da cidade severa e bárbara, crispada num reflexo intratável de desconfiança: na época arcaica, ao contrário, Esparta é um grande centro de cultura, acolhedora para com os estrangeiros, as artes, a beleza, para com tudo que pretenderá mais tarde repelir: é ela, então, aquilo 
que Atenas se tornará no século $\mathrm{V}$ - a metrópole da civilização helênica (MARROU, 1975. p. 34 -35).

Quanto a Atenas, afirma Marrou (1975, p. 65): "(em algum momento do sexto século), perdeu a educação seu caráter essencialmente militar”. Embora as práticas militares continuassem acontecendo, elas não desempenhavam mais um papel fundamental, sobretudo, na educação ateniense.

Segundo Marrou (1975), de um lado, a educação grega não perdeu seus laços com a nobreza, continuando a ser uma educação de nobres, pois era para uma elite privilegiada, que detinha poder, riqueza e tempo ocioso. Por outro, assiste-se a um movimento de "democratização da educação", através do aparecimento da escola destinada ao conjunto dos homens livres, dos cidadãos.

Para Jaeger (2003, p.174), o começo da formação política em Atenas inicia-se com Sólon. Trata-se da subordinação do indivíduo ao Estado, mas com um elemento diferenciador: a ideia de direito. Em um tempo de mudanças da ordem social, o direito era um ponto firme de apoio para o homem. Cambi (1999) também escreve que a ascensão de Atenas deu-se por intermédio da obra de Sólon (594 a. C), com uma constituição democrática.

Com a democracia surge, também, uma postura mais crítica em relação ao saber religioso e mitopoiético, favorecendo o livre pensar, o questionamento da tradição, cujos principais representantes são os sofistas. Segundo Jaeger (2003), é no tempo dos sofistas que se origina a crise do Estado. As lutas pelo poder interno depois da morte de Péricles e as ideias dos sofistas sobre a natureza e sobre a lei ameaçavam as possibilidades de um Estado ideal, baseado em valores políticos imutáveis.

Nesse momento, conforme Cambi (1999), a polis, enquanto organismo educativo, entra em crise, pois vai surgindo um novo modelo de homem desvinculado dos valores políticos e que constrói a si mesmo de maneira mais livre. As virtudes do homem não estão mais vinculadas aos costumes e à tradição, mas à sua formação, à sua individualidade, sustentada na frase socrática "conhece-te a ti mesmo". Em oposição à pedagogia do exemplo, que visava ao apego à família e ao Estado, nasce a pedagogia como saber autônomo. O Humanismo não é mais produzido pela natureza, mas através da educação. É no interior desses debates que a história do pensamento grego, em geral, e a reflexão aristotélica, especificamente, possuem grande importância.

\section{Educação e ética aristotélica: a questão do indivíduo}

Aristóteles (1992), ao desenvolver a sua obra Ética a Nicômaco, tem como intenção responder à seguinte questão: Qual o bem a que toda atividade humana visa, ou seja, qual é o bem supremo? É a partir desse problema que ele elabora suas ideias apresentando meios racionais para o alcance de tal bem.

Esse bem que ele pretende investigar é apresentado logo no seu primeiro livro, ao afirmar que as pessoas, de modo geral, concordam que nada há de mais valioso que a felicidade. A felicidade era compreendida, segundo Aristóteles (1992), de muitas formas, ou seja, associava-se a felicidade a diversas coisas, como a riqueza, a honra e os prazeres, mas ele recusava tais opiniões, argumentando que a dedicação aos prazeres tornava o homem semelhante aos animais. Aristóteles (1992) entendia que a felicidade estava ligada a três classes de bens: os da alma, os do corpo e os exteriores. Os bens da alma eram melhores que os exteriores, pois estes ajudam a ganhá-los e a mantê-los. Explica Sciacca (1968) que para Aristóteles o que há de melhor no homem é a razão, e uma vida só poderia ser feliz, na medida em que o homem buscasse, através das virtudes, viver conforme a razão. Viver bem significava viver segundo a razão, sendo que somente as virtudes poderiam garantir essa "vida boa". Diz Hadot (1999, p.124): "Parece que para Aristóteles a filosofia consiste em um modo de vida 'teorético"'. E, explicando tal afirmação, o autor demonstra que teorético, na visão aristotélica, não era algo que se opunha à prática, mas significava "uma filosofia praticada, vivida, ativa, que leva à felicidade" (HADOT, 1999, p.124).

Haveria, assim, uma profunda relação entre vida e conhecimento: filosofar para se aprender a viver melhor. Por isso, é clara a preocupação com a educação quando Aristóteles (1992) trata da influência do conhecimento na vida, pois as pessoas precisavam saber, precisavam aprender a refletir sobre suas vidas e seus modos de agir. No sentido proposto por Hadot (1999), a filosofia na Grécia também estaria a serviço da existência, fazendo parte do cotidiano, em um mo- 
vimento também passível de ser visto em Aristóteles.

$\mathrm{Na}$ Ética a Nicômaco é possível perceber a preocupação com a formação pessoal, com a aprendizagem de hábitos que levassem os sujeitos a serem melhores e, consequentemente, felizes. Lastória (2003, p. 430) afirma que:

Com Aristóteles, a ética deixará de ser vista como uma ontologia do Bem, tal como Platão a concebeu, adquirindo então o estatuto de uma disciplina própria com aplicação prática: praktiké episthéme. O imperativo socrático segundo o qual é necessário conhecer o que é o Bem, para que, desse modo, possamos tornar-nos melhores com relação àquilo que já somos, adquire em Aristóteles a feição de uma 'doutrina da vida reta'.

Aristóteles propõe na sua ética que o caminho correto para se chegar à felicidade seria através das virtudes e que estas podem ser ensinadas:

Em grande parte a excelência intelectual deve tanto o seu nascimento quanto o seu crescimento à instrução (por isso ela requer experiência e tempo); quanto a excelência moral, ela é produto do hábito, razão pela qual seu nome é derivado, com uma ligeira variação, da palavra 'hábito'. É evidente, portanto, que nenhuma das várias formas de excelência moral se constitui em nós por natureza, pois nada que existe por natureza pode ser alterado pelo hábito... Portanto, nem por natureza nem contrariamente à natureza a excelência moral é engendrada em nós, mas a natureza nos dá a capacidade de recebê-la, e esta capacidade se aperfeiçoa com o hábito (ARISTÓTELES, 1992, p.35).

Nessa citação, Aristóteles trata da questão da possibilidade do aprender. O papel da educação na formação do caráter é de fundamental importância. Os hábitos adquiridos por meio dos exemplos, de máximas populares, de castigos, de exortações acabariam por fixar nos alunos certas disposições, afirma Lastória (2003, p.443).

Aristóteles fala sobre a excelência moral, afirma que ela: "é uma disposição da alma relacionada com a escolha de ações e emoções, disposição esta consistente num meio termo (o meio termo relativo a nós) determinado pela razão (a razão graças a qual um homem dotado de discernimento o determinaria)" (ARISTÓTELES, 1992, p. 42). Portanto, a educação possibilitaria uma ação pautada no discernimento, no controle das paixões por intermédio do bom uso da razão. Ou seja, seria um dos principais objetivos da educação garantir ao membro da polis que este se apropriasse de valores que o possibilitassem conquistar, racionalmente, sua felicidade. Interessantemente, essa felicidade, em Aristóteles, relacionava-se com a vida em comunidade, fazendo com que a educação fosse vista, também, como relevante, ao fornecer subsídios para a formação de bons hábitos necessários para a vida social e política.

\section{Educação e política: a formação do cidadão no pensamento de Aristóteles}

Na relação entre educação e política o ponto norteador é a formação à cidadania. Conforme Jaeger (2003), o surgimento da estruturação jurídica da vida em sociedade deu ao homem uma segunda existência, ou seja, com a polis institui-se, socialmente, a vida pública ou política. Então temos o cidadão e o indivíduo, e as consequentes discussões sobre o que os unia ou os distanciava. Somam-se, tensamente, às virtudes individuais, as virtudes políticas.

Ética e política, no pensamento aristotélico, caminham lado a lado, uma completando a outra, de forma que o homem não era e nem tinha nada sem a cidade, pois era visto como um "animal político", por natureza. Nesse sentido, a política guiaria as outras dimensões filosóficas, como afirma Aristóteles (1992, p. 17):

(...) esta determina quais são as demais ciências que devem ser estudadas em uma cidade, e quais são os cidadãos que devem aprendê-las, e até que ponto; e vemos que mesmo as atividades na mais alta estima se incluem entre tais ciências, como por exemplo a estratégia, a economia e a retórica. Uma vez que a ciência política usa as ciências restantes e, mais ainda, legisla sobre o que devemos fazer e sobre aquilo de que devemos abster-nos, a finalidade desta ciência inclui necessariamente a finalidade das outras, esta finalidade deve ser o bem do homem.

Segundo Sciacca (1968, p. 104), "O objetivo do Estado não é apenas o de defender os cidadãos dos inimigos externos e internos, mas também de educar fisicamente e moralmente aqueles que participam da vida pública". Este último aspecto da vida pública é o que mais interessa a Aristóteles, levando-o a crer que um bom legislador é aquele capaz de persuadir seu 
povo a buscar o que é bom, para o indivíduo e para o Estado. O Estado deve oferecer condições para que os homens se tornem virtuosos através das leis e da educação, por isso a educação tem caráter público. Público, no sentido de dirigido pelo Estado, em acordo com as concepções deste. Temos aí, então, a finalidade da educação, que é a preservação do Estado não somente em seu aspecto territorial, mas principalmente em seu aspecto moral, que sustentaria a força de seu arranjo institucional.

Nesse ponto de vista, o indivíduo é concebido como subordinado aos interesses da cidade. Tanto que para os gregos antigos a cidade não significava o território, mas a coletividade dos cidadãos, ou seja, a cidade era o conjunto de seus cidadãos, de suas crenças, de seus costumes e de suas leis. Então, tornou-se difícil separar o homem do Estado. A importância do Estado e, dentro dele, da educação, fica explícita no pensamento do filósofo:

Como não há senão um fim comum a todo Estado, só deve haver a mesma educação para todos os súditos. Ela deve ser feita não em particular, como hoje, quando cada um cuida de seus filhos, que educa segundo suas fantasias e conforme lhe agrada; ela deve ser feita em público. Tudo o que é comum deve ter exercícios comuns. É preciso, ademais, que todo cidadão se convença de que ninguém é de si mesmo, mas todos pertencem ao Estado, de que cada um é parte e que, portanto, o governo de cada parte deve ter como modelo o governo do todo (ARISTÓTELES, 2002, p.78).

Diante do que foi exposto, é natural que a educação não fosse a mesma para cidadãos e não cidadãos, para homens livres e para escravos, e para trabalhadores e para os que podiam viver no ócio. É necessário entender que escravo não é somente aquele que pertence a outra pessoa, mas também, na concepção aristotélica e de outros gregos da época, como Platão, é aquele que não dispõe de tempo livre para dedicar-se aos assuntos da polis. Conforme Arendt, (1991, p.42), na vida privada os homens viviam juntos para sanar suas carências e necessidades que estão associadas à vida biológica, portanto não era na privacidade do lar que a liberdade existia. O lar não proporcionava a liberdade aspirada pelos gregos. Somente na esfera pública o homem tornava-se livre.

Saviani (2007) escreve que essa divisão dos homens em classes provocou também uma divisão na educação. Se antes o processo educativo estava, necessariamente, vinculado ao trabalho, o escravismo consolida o fato de haver duas modalidades de educação:

(...) uma para classe proprietária, identificada como a educação dos homens livres, e outra para classe não proprietária, identificada como a educação dos escravos e serviçais. A primeira, centrada nas atividades intelectuais, na arte da palavra e nos exercícios físicos de caráter militar. E a segunda, assimilada ao próprio processo de trabalho (SAVIANI, 2007, p. 05).

Saviani (2007) pontua que a paidéia era a educação dos homens livres e a duléia implicava a educação dos escravos no próprio ambiente de trabalho.

(...) a escola, desde suas origens, foi posta do lado do trabalho intelectual; constituiu-se num instrumento para a preparação dos futuros dirigentes que se exercitavam não apenas nas funções da guerra (liderança militar), mas também nas funções de mando (liderança política), por meio do domínio da arte da palavra e do conhecimento dos fenômenos naturais e das regras de convivência social. Como já foi pontuado, isso pode ser detectado no Egito desde as primeiras dinastias até o surgimento do escriba, assim como na Grécia, em Roma e na Idade Média, cujas escolas, restritas, cumpriam a função de preparar os também restritos quadros dirigentes (intelectuais) então requeridos. Nesses contextos, as funções manuais não exigiam preparo escolar (SAVIANI, 2007, p.8).

Nesse sentido, é preciso ter claro que Aristóteles não escreveu sobre uma educação geral e popular tal como passou a ser debatido nos séculos XVIII e XIX d.C., mas sobre uma educação específica, de um grupo específico. Suas teorias sobre a educação não poderiam ser aplicadas a qualquer indivíduo, mas àqueles capazes de cumprir plenamente o ideal de educação proposto, e por isso tal forma de educação não é compatível com a vida do artesão, do escravo e mesmo das mulheres.

Na obra $A$ Política Aristóteles dedica um espaço especial para tratar da educação. Ele inicia o assunto da seguinte forma:

Como é a própria virtude que, em nosso sistema, faz o bom cidadão, o bom magistrado e o homem de bem, e como é preciso começar obedecendo antes de comandar, o legislador deve cuidar principalmente 
de formar pessoas honestas, procurar saber por quais exercícios tornará honestos os cidadãos e, sobretudo, conhecer bem qual é o ponto capital da vida feliz (ARISTÓTELES, 2002, p. 65).

Aristóteles (2002) relaciona a educação e a alternância entre os estados de guerra e de paz. Nesse ponto ele faz uma crítica aos legisladores que se preocupavam em voltar os fins da educação para a guerra, pois via que nessa atitude a guerra levava consigo toda a possibilidade de felicidade e virtude, por consumir esforços e recursos na vontade de vencer seus vizinhos e expandir seus impérios: "Deve-se criticar o legislador que não lhes ensinou como viver em paz (...) Não resta dúvida, portanto, de que se devam cultivar de preferência as virtudes pacíficas" (ARISTÓTELES, 2002, p. 68). Nas palavras de Aristóteles (2002) é possível perceber o novo homem, muito diferente dos tempos homéricos, em que todas as virtudes se voltavam para a valentia no campo de batalha. O homem novo, político, desfrutaria de seu tempo ocioso para pensar as coisas belas e significantes relacionadas à vida espiritual.

\section{A ética e a política a serem realizadas por uma educação}

Tendo por base essas considerações mais amplas sobre a relação entre educação, filosofia e política na Grécia, Aristóteles também elabora algumas ponderações mais especificamente educacionais. Para ele, três coisas contribuem para a formação do homem: a natureza, o hábito e a razão. Lança então uma pergunta bastante inquietante: "Resta saber se para formar os homens mais vale começar pelo raciocínio ou pelo hábito (...) a razão e o intelecto são a principal e derradeira parte onde se manifesta em nós a obra da natureza. Cumpre, portanto, subordinar-lhes a obra da geração humana e a formação dos costumes" (ARISTÓTELES, 2002, p. 69- 70). No entanto, explica que assim como o corpo é formado antes da alma, a parte que não possui razão é gerada antes do que aquela que participa da razão. O que comprovaria sua observação seria o comportamento das crianças, com suas manifestações de cólera, desejos e vontades desde o nascimento até o momento em que começassem a existir as condições para um predomínio da razão. Depois de todas essas explicações, responde à pergunta afirmando: “... o raciocínio e a inteligência só lhes vêm naturalmente com a idade. Convém, portanto, dar as primeiras atenções ao corpo, as segundas aos instintos da alma, recorrendo-se, todavia, ao intelecto ao tratar dos apetites e à alma, ao tratar do corpo" (ARISTÓTELES, 2002, p. 70).

Por isso, Aristóteles (2002) inicia suas considerações educacionais dirigindo-as à alimentação dos recém-nascidos, apontando como elemento principal o leite em abundância, assim como o uso de diversos movimentos para prevenir seus corpos da preguiça e do peso. Afirma que desde o início é bom acostumar a criança ao frio, por causa das práticas militares posteriores. Qualquer prática posterior dependeria dos hábitos.

Até os sete anos, a educação caberia à família e esta deveria cuidar para que a criança não conversasse muito com os escravos, e também deveria ser afastada de tudo o que ferisse o pudor. Aristóteles defende que eram as primeiras impressões as que mais afetavam as crianças. Com esse embasamento, a educação, a partir dos sete anos, tomaria um caráter mais formal:

Aos sete anos, a educação divide-se em dois grupos, um até a puberdade, outro da puberdade até os vinte e um anos. Não há de aprovar, segundo cremos, a partilha que fazem certas pessoas que dividem toda a vida de sete em sete anos. Mais vale seguir o ritmo da natureza. Ela apenas esboçou suas obras. A obra da educação, assim como de todas as artes, deve unicamente completar o que falta ao ser das obras da natureza (ARISTÓTELES, 2002, p. 77).

Com relação ao programa de ensino, uma questão preocupava Aristóteles: o que ensinar e o que era, realmente, importante de receber atenção: "Não se sabe se deve ensinar as crianças as coisas úteis à vida ou as que conduzem às virtudes, ou as altas ciências, que se pode dispensar" (ARISTÓTELES, 2002, p. 78). Defende que se deveria começar aprendendo as coisas necessárias; porém, nem todas elas. E que é preciso exercícios que não tornem nem o corpo e nem a alma incapazes da prática das virtudes, como é o caso de "todos os trabalhos mercenários e os ofícios que deformam o exterior e aviltam ou fatigam o intelecto" (ARISTÓTELES, 2002, p. 79). Quanto às ciências, elas deveriam ser aprendidas com moderação.

Aristóteles (2002, p. 79) afirma, ainda: "Há mais ou menos quatro coisas que de ordinário se ensinam às crianças: $1^{\circ}$ as letras; $2^{\circ}$ a ginástica; $3^{\circ} \mathrm{a}$ 
música; alguns acrescentam em $4^{\circ}$ a pintura; a escrita e a pintura para as diversas circunstâncias da vida; a ginástica por servir para educar a coragem". Quanto à escrita e a pintura, ele se restringe a esse comentário, mas tratará detalhadamente da música e da ginástica.

Em seus comentários sobre a música, Aristóteles afirma que ela não possuía o devido reconhecimento. No seu modo de ver, a música era "o princípio de todos os encantos da vida" (ARISTÓTELES, 2002, p. 80). Ele a defende não por ser ela necessária à educação como um todo. Segundo ele, a música tornaria agradável o lazer.

Quanto à ginástica, Aristóteles via que ela vinha ao encontro dos cuidados com o corpo, vistos como fundamentais:

Já que se deve começar por imprimir hábitos nas crianças antes de instruí-las pelo raciocínio e moldar seu exterior antes de trabalhar seu intelecto, concluímos com a ginástica e a pedotríbica: uma fortifica o temperamento, a outra dá graça às ações (ARISTÓTELES, 2002, p. 82).

No entanto, mostra que devem existir alguns cuidados com relação à ginástica. Não se deveriam usar exercícios que deformassem o corpo e que causassem excesso de fadiga. Cabe reforçar que Aristóteles faz uma crítica bastante severa ao exagero das práticas do ginásio em detrimento da instrução, argumentando que tais práticas tornam jovens "reles guarda-costas" (ARISTÓTELES, 2002, p. 83). Nesse ponto, para ponderar sobre esse ambicionado equilíbrio na educação, Marrou (1975) nos oferece uma importante análise para verificar o quão dependente das transformações sociais está a realização das ideias educacionais:

Aqui, devo exorcizar um mito moderno, o de uma síntese harmoniosa entre 'a beleza da raça, a perfeição suprema da arte e os mais altos vôos do pensamento especulativo' que a civilização helênica teria podido realizar plenamente. Esse ideal de um espírito plenamente desabrochado num corpo soberbamente desenvolvido, não é, sem dúvida imaginário; [...] Mas é necessário considerar também que, se ele pôde realizar-se na prática, só o pôde num instante fugidio de equilíbrio instável entre duas tendências que evoluíam em sentido contrário, e das quais somente uma pôde progredir, acarretando a regressão da primeira, de início dominante (MARROU, 1975, p. 75) (Sem grifos no original)
Marrou (1975) nota que a educação grega assume uma característica cada vez mais intelectual e ligada à técnica oratória, manifestando, com isso, a deterioração das condições de manutenção da hegemonia helênica, em um processo que a educação aristotélica busca fazer frente. Dito de outra maneira, a perspicácia da filosofia de Aristóteles, ao pensar a educação e relacioná-la com a vida política, não foi força suficiente para impedir as transformações que levaram ao declínio político e econômico da Grécia.

\section{Referências}

ARENDT, Hannah. A condição humana. Tradução de Roberto Raposo. 2. ed. Rio de Janeiro: Forense Universitária, 1991.

ARISTÓTELES. A política. Tradução de Roberto Leal Ferreira. São Paulo: Martins Fontes, 2002.

ARISTÓTELES. Ética a nicômaco. Tradução de Mário da Gama Cury. 2. ed. Brasília: UNB, 1992.

BARKER, Ernest. Teoria política grega: Platão e seus predecessores. Tradução de Sérgio Fernandes Guarischi Bath. Brasília: UNB,1978.

CAMBI, Franco. História da pedagogia. Tradução de Álvaro Lorencini. São Paulo: UNESP, 1999.

GILES, Thomas Ranson. História da educação. São Paulo: EPU, 1987.

HADOT, Pierre. O que é filosofia antiga? Tradução de Dion Davi Macedo. 2. ed. São Paulo: Loyola, 1999.

HOURDAKIS, Antoine. Aristóteles e a educação. Tradução de Luiz Paulo Rouanet. São Paulo: Loyola, 2001.

JAEGER, Werner. Paidéia: a formação do homem grego. Tradução de Artur M. Parreira. São Paulo: Martins Fontes, 2003.

LASTÓRIA, Calmon Nabuco. Impasses éticos na educação hoje. Revista Educação e Sociedade, Campinas, vol 24, n.83, p.429-440, agosto de 2003. Disponível em: $<$ http://www. cedes.unicamp.br>. Acesso em: 10 abr. 2009.

MANACORDA, Mário Alighiero. História da educação: da antiguidade aos nossos dias. Tradução de Gaetano Lo Mônaco. 3. ed. São Paulo: Cortez: Autores Associados, 1992.

MARROU, Henri Irénée. História da educação na antiguidade. Tradução de Mário Leônidas Casanova. São Paulo: E.P.U, 1975.

MORRAL. Aristóteles. Tradução de Sérgio Duarte. 2. ed. Brasília: UNB, 1985.

PONCE, Aníbal. Educação e luta de classe. Tradução de José Severino de Camargo Pereira. 14. ed. São Paulo: Cortez, 1995. 
REALE, Giovani. Historia da filosofia antiga. Tradução de Henrique Cláudio de Lima Vaz/ Marcelo Perine. 2. ed. São Paulo: Loyola, 1994.

SAVIANI, Dermeval. Trabalho e educação: fundamentos ontológicos e históricos. Revista Brasileira de Educação v.12 n.34 jan./abr.2007. Disponível em: <http://74.125.47.132/ search?q=cache:Bb5u54BUaSEJ:www.scielo.br/pdf/rbedu/ v12n34/a12v1234>. Acesso em: 30 maio 2009.

SCIACA, Michele Federico. História da filosofia: Antiguidade e Idade Média. Tradução de Luís Washington Vita. São Paulo: Mestre Jou, 1968. 